This is a peer-reviewed, accepted author manuscript of the following article: Hart, T. G. B., Booyens, I., \& Sinyolo, S. (2020). Innovation for development in South Africa: experiences with basic service technologies in distressed municipalities. Forum for Development Studies, 47(1), 23-47. https://doi.org/10.1080/08039410.2019.1654543

\title{
Innovation for Development in South Africa: Experiences with Basic Service Technologies in Distressed Municipalities
}

Tim G.B. Hart, Irma Booyens and Sikhulumile Sinyolo

\begin{abstract}
South Africa's National Development Plan entrenches the importance of a capable developmental state for the country's social and economic development. Likewise, the potential of science, technology and innovation to address development challenges is emphasised. The developmental state and inclusive innovation ideas have been in and out of the policy agenda since 1996 but have recently gained renewed policy attention. As part of an inclusive innovation for development agenda, the Department of Science and Technology facilitated the demonstration of a suite of basic service innovations in 'distressed' municipalities. This paper, using a mixed-methods approach, draws on the assessment of these demonstrations to reflect on key features which come to the fore in both the developmental state and inclusive innovation literature as crucial for success. In order to enjoy a measure of success in terms of developmental states and inclusive innovation for development, similar conditions are necessary: the encouragement and fostering of active participation by all stakeholders; sufficient financial resources and human capabilities at all levels; and strong collaborative and cohesive networks with similar purposes in mind. Once these form part of practice we are likely to see better implementation of inclusive innovation for development.
\end{abstract}

Keywords: Inclusive innovation; developmental state; public sector innovation; innovation capabilities; networked governance; basic services 


\section{Introduction}

In recent decades the South African government introduced at least two primary approaches to mitigate increasing inequality, unemployment and poverty (Seekings and Nattrass, 2006). One is the promotion of a developmental state incorporating developmental local government institutions (NPC, 2012). The developmental state has been correlated with high economic growth through innovation and competitiveness (Johnson, 1999), especially among the East Asian autocratic states, although there exist more egalitarian versions following the Scandinavian developmental welfare state (Bernard and Boucher, 2007). While promoting the developmental state, South Africa has emphasised wealth-redistribution, extending the scope and value of social grants and other welfare transfers from 2000 (Burger, 2014; Seekings and Nattrass, 2006), thereby giving development an incredulous welfare slant. The second approach is the adoption of a National System of Innovation (NSI) model in pursuit of innovation for economic growth and competitiveness. South Africa recognises the potential of science, technology and innovation (STI) to address development challenges (DST, 2018; RSA, 1996a; Wild, 2015), which includes enterprise competitiveness and meeting basic community needs. Thus, South Africa aligns itself with the African Union STI twenty-year strategy (AU, 2014) and, as one of the more influential actors in the AU, strives to shape the direction of the African STI frontier.

After 1994, development planning that includes basic service delivery has become a significant mandate of local government (Madumo, 2015; Rogerson, 2018). A particular focus for the South African NSI is to include poorer segments of the population into the innovation system, either as beneficiaries or co-creators of innovations (DST, 2013, 2015, 2017; RSA, 1996a). However, how this is to be practically achieved has yet to be clearly outlined and the Draft White Paper on Science and Technology is more rhetorical than pragmatic in this regard (DST, 2017; Walwyn and Cloete, 2018). 
The Department of Science and Technology (DST) recognises a rather simple definition of 'inclusive innovation' (Schillo and Robinson, 2017), which is largely redistributive and speaks to the creation or provision of innovative solutions to the challenges of the poorest, 'with or without ... [their] ... involvement in the process itself” (DST 2017:23). In practice, the emphasis has been on basic service improvement and delivery, to the detriment of local economic development more broadly (Ndabeni et al., 2016). There has been little participation by, and acknowledgement of the innovative actions, on the local level, particularly of the poorest in rural distressed municipalities (Hart et al., 2014; Khambule, 2018). South Africa, like other developing countries, requires a multidimensional approach to innovation and technology adoption for inclusive growth and development (Charles et al., 2017; Khambule, 2018; Schillo and Robinson, 2017; Sheikheldin and Devlin, 2018).

Despite commonalities in their intentions (i.e. improved social and economic well-being), improvements from the adoption of a democratic developmental state and innovation for inclusive development (IID) agenda (RSA, 1996a) have been slow to materialise and with mixed outcomes (Burger, 2014; NPC, 2012; Petersen and Kruss, 2018). The existing version of the developmental state in South Africa bears little resemblance to that of the East Asian 'tiger' model venerated in the 1990s; fragile resemblance to the Anglo-Saxon model of countries such as Canada that drove the NSI transformation in South Africa during the 1990s; and weak resemblance to the Scandinavian experience (Bernard and Boucher, 2007; Chang, 2010). The National Development Plan (NDP), which guides South Africa's overall development until 2030 (NPC, 2012), is ominously silent on defining the developmental state (Burger, 2014) or IID. It invokes variations of the developmental state but adopts none. The NDP, however, emphasises that 1) South Africans must 'participate fully in the economic, social and political life of the country, supported by good-quality education, health care, transport and other basic services' (NPC, 2012: 44) thus noting their inclusion; and 2) reiterates 
the importance of innovation for social and economic development. However, local-level basic service delivery innovations have generally been characterised by top-down provision rather than democratic bottom-up identification or even local user input (see Booyens and Hart, 2019; Hart et al., 2019).

To support the provision of innovation driven municipal services, the DST convened the Innovation Partnership for Rural Development (IPRD) in 2011. The intention of this partnership is to pool the skills and knowledge of a number of STI actors, which include South African universities, science councils and public officials working in 27 priority or 'distressed' district municipalities. The Department of Rural Development and Land Reform identified these districts as being under-developed, under-resourced and suffering basic service delivery backlogs (Ndabeni et al., 2016). Given their close proximity to residents and the diverse needs of the assorted human settlements within their boundaries, district municipalities, together with local municipalities located within them, perform important basic developmental and service delivery roles (RSA, 1998; Rogerson, 2018; Van der Waldt, 2015). Basic services include refuse removal, the provision of sanitation, potable water and electrification, many of which are stipulated in the South African Bill of Rights (see Ramoroka et al., 2017; RSA, 1996b). Beyond service delivery, municipalities perform the necessary 'inclusive' link between residents and provincial and national tiers government. To be effective in these roles, they must have the necessary resources, human capabilities, networks and understanding of residents' needs and aspirations.

This article interrogates the inclusive innovation-developmental local government nexus in distressed municipalities with respect to recent demonstrations of innovations that could lead to improved basic service delivery. These demonstrations were implemented from 2013 as part of the Innovation Partnership for Rural Development Programme (IPRDP), one of several rural development innovation-oriented programmes by the IPRD. A mixed-method approach is 
adopted, drawing from a national study to assess the demonstration process of eight basic service delivery innovations, involving water, sanitation, and electrification; and how the communities experienced the roll-out of these innovations in the sampled municipalities. According to Burger (2014), the strategic features of the developmental state require collaborative and strongly linked structures along with the long-term availability of resources. These features are also necessary for enhancing inclusive innovation aimed at development (Klijn and Koppenjan, 2016; Lundberg and Hovik, 2014). Therefore, the strength of inclusive Public Sector Innovation (PSI) demands strong networks, investment in financial and human resources, and officialdoms with innovation capabilities to enable the introduction of innovations along with balancing the requirements necessary for enhancing economic growth, governance and social well-being. Such features are particularly crucial to a state that proposes democratic and inclusive ideals around development and innovation.

Key areas of interest for this paper are therefore 1) the quality of innovation networks, 2) their inclusive and/or participatory nature in the innovation value chain, and 3) the sustained availability of resources, which includes the innovation capabilities of local government institutions and personnel. As a young democracy with aspirations of economic growth and socioeconomic equality, South Africa provides the ideal case for exploring this intersection. While the focus is on demonstrating PSI in distressed municipalities, the findings presented in this paper could apply to settlements and local authorities near urban metropolitan areas, given the similarities in these localities, i.e. low income, limited basic services and infrastructural gaps, low encouragement of participation, limited resources, low officialdom capabilities and little access to NSI activities and products. These features are common to other developing middle-income countries, making our findings globally relevant. Moreover, the lessons learnt from the South African experience bears relevance to countries who style themselves as development states and who endeavour to employ pro-poor or developmental innovations. For 
instance, these would be countries like Vietnam, Argentina, India and Peru (see Habiyaremye et al., 2019). This paper contributes to an emerging literature on the role of the state in innovation and the experience of the mentioned countries in implementing STI to address service delivery challenges like improving sanitation and electricity provision, particularly in rural areas.

The next section considers the transformations of the development state concept and the model emerging in South Africa and the inadequacy of PSI in this model. As noted above key criteria of the developmental state align with notions of PSI and IID, therefore the third section looks at their features and purpose and thus relevance in the international and South African contexts in terms of pro-poor development. As the main platform to improve wellbeing through service delivery innovation across 23 of the 27 priority municipal districts, the IPRDP is summarised in section four. The fifth section discusses the research methods used in this study to investigate levels of community user participation and encouragement, the extent of municipal innovation capabilities and the effectiveness of innovation networks. Section six presents the findings in light of these three subsections. The final section concludes that there is a huge gap between the development state and IID rhetoric promoted by the state and its innovation organs and what occurs as innovation practice on the ground in these district municipalities.

\section{The South African Developmental State}

While the NDP posits the achievement of a 'capable and developmental state' (NPC, 2012: 26), it fails to clarify what this means and what form it should take. Yet, it considers innovation as integral to the developmental state and a precursor to driving growth, development and reducing inequality.

Johnson's (1982) thesis on the expansion of the Japanese economy between 1950 and 1980 introduced the 'developmental state' concept, that is a state characterised by exceptional 
economic growth. In the Japanese example, government played a powerful role in supporting the economy by favouring private sector manufacturing industries, seemingly at the cost of human rights, wages and equality. This phenomenal industrialisation coincided with that of other, mainly political authoritarian states, with an emphasis on manufacturing sectors and innovation to ensure their competitiveness. Other countries that followed a similar path, include Taiwan, South Korea, Singapore, and later China with its version of state-capitalism. Brazil has been included in this mix this century (Burger, 2014), although it compares better to the Scandinavian examples (Bernard and Boucher, 2007).

Chang (2010) broadens the developmental state concept by incorporating the Scandinavian, social democratic welfare states. According to Chang, these states achieve their legitimacy by ensuring a balance in realising equality and growth through government interventions and welfare policies. Evans (2010) and Behuria and Goodfellow (2018) argue that in the $21^{\text {st }}$ century the developmental state is moving away from manufacturing to the knowledge economy, emphasising the prominence of service sectors. Drawing on the work of Amartya Sen, Evans (2010) highlights the need for the public and private sectors to focus on education, health, services, and expanding human and organisational capabilities. This is a shift from the East Asian models with their reliance on low wages, largely unskilled labour, uneven development, uncertain human and labour rights and an emphasis on export-oriented industrialisation for economic growth (see Nordhaug, 2012; Tria Kerkvliet, 2010).

This contemporary human development and social welfare emphasis leads Bernard and Boucher (2007) to delineate three types of states - the liberal state, the social investment state and the transfer welfare state - with different emphases on their developmental features. According to Bernard and Boucher (2007), the liberal state places the responsibility of social welfare on individuals who must ensure that their education, pension, health and welfare demands are primarily met through own investments. The state plays a minimalist role in 
reducing inequality and spends little on social goods. In contrast, the social investment state, actively invests in its citizens and provides for everyone by caring for dependents, ensuring quality health care, and providing life-long education and learning. Investment in these areas is considered crucial to ensure the overall wellbeing of citizens to realise productive work and competitiveness, which are necessary to provide the tax-base required to fund extensive highquality social goods. Social investment states have shown strong ability to achieve significant growth and social investment (Bernard and Boucher, 2007; Chang, 2010). The transfer welfare state entails larger but passive social transfers in the form of unemployment insurance, old-age pensions, disability and other social grants. It includes generous unemployment compensation and even premature retirement compensation (Bernard and Boucher, 2007). The challenge is that these high expenditures require a high tax-base but are unlikely, in most cases, to lead to growth while reducing inequality.

South Africa appears to be on a transfer welfare state path. There has been extensive and increased social spending on pensions, child grants and other welfare transfers since 2000 (Seekings and Nattrass, 2006). Almost $60 \%$ of government spending focuses on social services and welfare transfers, yet the working age population receives none of these transfers directly. Despite initial but short-lived post-1994 economic growth and the broader introduction of social goods and services to reduce existing inequalities, these changes have not manifested in the Asian, the liberal or the social investment developmental state models (Burger, 2014; Evans, 2010). In South Africa, growth is mitigated by strong labour unions; the Constitution that protects human rights and curtails attempts at authoritarianism; and the inability to unleash an export driven service-based economy and promote industrialisation (Booyens and Hart, 2019; World Bank, 2018). A recent report on poverty (Stats SA, 2017) describes economic growth in South Africa as weak, attributing this to both the aftermath of the 2008 global economic downturn and the failure of the government to effectively tackle inequality, unemployment and 
poverty problems. In June 2015, unemployment of the working age population reached a 14year high of $36.4 \%$ of the eligible workforce and extreme food poverty increased to $25.2 \%$ of the population - a 4\% increase in as many years (Stats SA, 2017). In 2015 household debt increased to $77 \%$ and a third of all households relied on welfare transfers in the form of social grants (Stats SA, 2017). Saving and investment are extremely low in South Africa (Burger, 2014), providing little capital to protect future economic growth and sustainable development or promote innovation. Poor social services further exacerbate poverty rather than enable people to move out of poverty, and in so doing places an increasing burden on the fiscus, reducing the investment capability necessary for social welfare and economic innovation (van der Berg et al. 2010). Burger (2014) argues that the lacklustre economy has failed to stimulate widespread innovation. According to the World Bank (2018), there is a need for tangible innovation within the state bureaucracy to stimulate economic competitiveness. However, a more pressing concern is the need to also provide the financial and human resources for social investment. These are generally lacking and the NSI focuses primarily on the knowledge economy and global grand challenges (Wild, 2015).

\section{The Public Sector, Innovation and Pro-poor Development}

Internationally, PSI is firstly concerned with addressing the challenges faced by the public sector, and secondly at advancing public services (Ramoroka et al., 2017). Indeed, Bland et al. (2010) differentiate PSI, from that of the private sector, as being entirely devoted to providing public or social goods and services. Therefore, public goods with public value should be the intended outcomes of innovation by government agencies. The PSI role of government includes achieving particular social developmental outcomes, such as enhancing social cohesion and equality, poverty reduction, wealth distribution, job creation, environmental protection, safety and security, education and health care (Bloch and Bugge, 2013). Such intentions resonate with 
the South African Constitution and developmental local government imperatives (Ramoroka et al., 2017; RSA, 1996b). Additionally, the prerogative of governments in developing contexts is not only to deliver improved public services that will benefit society, but importantly to direct their efforts at improving the plight and circumstances of the poor (Ramoroka et al., 2017). This means that something more than large-scale welfare transfers is required; especially in the context of countries with poverty, unemployment and inequality levels similar to South Africa, where innovative social developmental outcomes are crucial (see Habiyaremye et al., 2019).

With regard to public value, innovation in the public sector is also associated with improving the operations of public organisations (Albury, 2005). This might include new governance structures, such as new institutional arrangements or organisational forms in local government to enable them to improve upon the delivery, inclusiveness and accountability of public services. According to Mulgan and Albury (2003) effective governance, which ensures public service delivery, depends entirely on innovation to improve performance and enhance public value in response to societal needs. At the same time, creating an enabling environment for innovation also relies on leadership, governance and the quality of institutions (Klijn and Koppenjan, 2016; Lewis and Ricard, 2014). Accordingly, in the context of innovation Rodríguez-Pose and Di Cataldo (2015) argue that the quality of institutions depends on control of corruption, rule of law, government effectiveness and government accountability. These considerations are admittedly constrained within the South African environment in the light of Auditor General reports which have indicated deteriorating accountability among municipalities (AG, 2019) and State Capture allegations (Meinotti and Masterson, 2018) which raises the question of whether government institutions are geared towards improving service delivery or are capable of innovation. This said, it is argued that innovation holds potential to facilitate learning by government officials and organisations towards improving organisational efficiency, the quality of public services and also public sector governance (see Mulgan and 
Albury 2003). Indeed, learning is of central importance in the open or networked approaches to innovation (Lundvall 2009; von Hippel 2005). Therefore, capabilities and institutions which enable innovation and the role of innovation to improve public sector outcomes appear to be mutually reinforcing. Nonetheless, the impact of embedded public sector corruption which arguably impede the ability of officials to innovate cannot be ignored. Yet, political and structural change is needed to overturn this dilemma.

In South Africa, the policy emphasis is on how things can be improved through a focus on innovation (see Ramoroka et al., 2017). This notion certainly is idealistic, but it also is pragmatic. The emphasis on innovation to address development challenges is not unique to South Africa, but also comes to fore in other global South contexts in which the role of STI to enhance access to basic public services, health care, education, and ensure food security are underscored (see AU, 2014; OECD, 2012, 2015). Policy instruments in developing countries often emphasise the dual imperatives of STI to ensure economic growth and competitiveness, along with benefits to the poor. These policy foci are evident in South Africa (DST, 2017; RSA, 1996a) which points to evidence of 'policy borrowing'. Innovation that benefits the poor is often styled as 'inclusive innovation', which can be understood as '...initiatives that serve the welfare of lower-income groups, including poor and excluded groups' (OECD, 2015: 9). The four aspects of inclusivity often highlighted in the literature relate to the relevance of problems addressed by innovation for the poor; the participation of the poor in the innovation processes; the ability of the poor to adopt the innovations; and the impacts of the innovations on the poor's wellbeing (Cozzens and Sutz, 2012; Foster and Heeks, 2013).

In South Africa, these inclusive innovation imperatives culminate in the IID agenda which ambitiously embraces both innovation for the benefit of the poor by the state and innovation undertaken by the poor as part of an agenda for IID (DST, 2017), the latter is also referred to as 'grassroots' or 'informal' innovations (OECD, 2015; Petersen et al., 2016). However, these 
concepts are often blurred and used as necessary superficial motivating metaphors to assemble support for diverse intentions. Schillo and Robinson (2017:35) warn that 'superficial implementation of inclusiveness concepts is unlikely to lead to the achievement of economic, social and environmental [development] goals'.

In democratic and inclusive paradigms, one issue of concern is that of participation by users or beneficiaries of innovation (Von Hippel, 2005). In the context of IID, the poor should not merely be seen as passive users or beneficiaries of innovation, but be encouraged to participate actively in innovation processes as innovators in their own right (Hart et al., 2015; Phiri et al., 2016). Indeed, user innovation entails problem-solving by users to improve the products and services they consume (Von Hippel, 2005). Moreover, user innovation forms part of open innovation approaches which are crucial for PSI (Djellal et al., 2013). The NDP emphasises community participation in development initiatives, and while bulk service delivery and innovation for the poor may not always require participation by local communities (DST, 2017), community participation is particularly important to achieve IID through democratic processes in contexts, like South Africa, where communities have been historically excluded and marginalised, and continue to be so (Seekings and Nattrass, 2006). While participation is a buzzword in the South African and indeed global development discourse, it is often vaguely defined, with different practices that are labelled as participatory, paying limited attention to who is participating, in what and for whose benefit (Cornwall, 2008).

The public sector, and its agencies, has a specific role in motivating parties to collaborate for social change and economic growth, and encouraging stakeholders to employ appropriate innovations to address the challenges faced by the poor (Hart et al., 2015). Networked governance emphasises alliances among government departments and agencies with external actors to heighten learning, collaboration, knowledge exchange and thus innovation (Ansell and Torfing, 2014; Bloch and Bugge, 2013; Klijn and Koppenjan, 2016). To optimise networks, 
learning organisations must have porous boundaries that allow new ideas and technologies to flow into and out of them, and ensure that the transfer of knowledge will foster innovation on a network level (Lundvall, 2009; Von Hippel, 2005). This is a stark shift from the traditional, bureaucratic and closed systems that characterise many government agencies, including those in South Africa.

The innovation literature underscores the importance of highly skilled human resources, access to financial resources, and strong institutions for innovation (Rodríguez-Pose and Di Cataldo, 2015), but these are reportedly constrained in South Africa and hamper innovation at the national and local levels alike (Ndabeni et al., 2016; Ramoroka et al., 2017). Debates around local economic development in South Africa emphasise that human capabilities and resources in small towns and rural areas are particularly weak (Nel et al., 2009; Rogerson, 2014). Moreover, effective institutional support and governance for local economic development, as well as systems for innovation, need to be enhanced in the local context (Hart et al., 2014; Kruss and Lorentzen, 2011; Phiri et al., 2016). Lundberg and Hovik (2014) propose collaborative governance systems, based on the inclusive and broad mobilisation of local actors, as a framework for collaborative rural governance - this links with ideas on networked governance outlined above. Their intention of including and mobilising local actors suggests that actors have to be more than just a passive 'presence', but be active in the structures and process of collaborative governance systems.

\section{An Overview of the IPRDP Basic Service Delivery Innovations}

The IPRDP focuses on the demonstration of eight locally developed (or improved) technological innovations to advance the quality and quantity of basic services for human settlements in 23 distressed districts. Table 1 describes the technologies, while Figure 1 illustrates their location. 
[Insert Table 1]

The demonstration phase had a planned budget of ZAR 143.5 million (DST, 2013:19-21), subsequent to which the district and local municipalities were expected to expedite the rollout of the innovations at their own cost or using government grants. By February 2016, 23 district municipalities were participating in at least one of the eight different technology demonstrations. The broad aim of the demonstration exercise was to introduce and test these service delivery technological innovations in identified municipalities. The implementation of demonstrations was completed in late 2017.

\section{Research Methods}

Data was collected from a sample of intervention sites (where the IPRDP demonstration was rolled out) and non-intervention sites (where no demonstrations occurred) in eight purposively identified distressed districts (Figure 1). A mixed method approach was followed, which included a random household survey in both sites, i.e. a Community Impact Assessment (CIA); several interviews with municipal officials and other stakeholders (a total of 14 key informant interviews [KII] conducted between June 2015 and October 2016); and field observations and discussions at the 15 sites throughout the course of the research project. Qualitative information on networks was drawn from the 14 KII conducted and field discussions. The CIA survey consisted of two rounds: a baseline $(N=857)$ carried out in March 2017, and a follow-up, postinterventions round $(N=652)$ conducted in March 2018, targeting the same households. In addition, a survey of municipal officials was conducted using the Municipal Innovation Maturity Index (MIMI) instrument to assess their innovation capabilities and the innovation maturity of employer municipalities. Officials involved in the IPRDP initiatives at their respective municipalities along with their managers were interviewed. Two survey rounds of the MIMI were completed - a baseline in November $2016(N=34)$, and a follow-up survey in 
November $2017(N=30)$. Junior, middle, and senior officials at local councils were included, i.e., officials at both the management and operational levels. The two samples were pooled $(N=64)$ for the descriptive analyses presented in this paper.

[Insert Figure 1 Map]

Our paper presents selected findings that speak to issues related to inclusive user participation, innovation capabilities and innovation networks. Firstly, we reflect on issues concerning community inclusiveness, understood as households' participation or some involvement in the decision making regarding the design or choice of demonstrated innovations. Secondly, selected findings on the innovation readiness or maturity of local municipalities to adopt and implement innovations are presented, and thirdly qualitative observations pertaining to issues of networking and collaboration are interrogated.

\subsection{User Participation/Inclusiveness}

Heeks et al. $(2013$; 2014) present a ladder comprising of six levels of IID, as a set of steps towards greater levels of innovation inclusion. Our focus is on Level 4 of inclusiveness, which deals with including the marginalised communities in the innovation process (invention, design, development, production and distribution). In line with the participation ladder of Arnstein (1969) and the approach of Heeks and colleagues, we designed questions that present the substeps of being included in the innovation process in order to ascertain the extent of inclusiveness operationalised by officials and their agents. The four questions asked if any members of the household had been informed/notified of the technology; consulted about or involved in identifying the type of technology or where it was implemented; involved in selecting the technology from those on offer; or had been involved in the design of the technology. These 
questions were included in the follow up CIA survey instrument (i.e. CIA 2) that aimed at investigating the experiences of households with the technology demonstrations, and the perceived impacts of these technologies on those involved.

\subsection{Innovation Capabilities}

The MIMI is a custom-designed tool for measuring human innovation capabilities at local government level in South Africa. The broad objective of the instrument is to determine the 'innovation readiness' of local municipalities to adopt innovations. Municipal officials, involved in the IPRDP, were asked to rate their own activities and their organisations in relation to innovation knowledge, opportunities, activities and practices. The framework consists of four constructs and 33 items. The constructs assess the extent to which:

a) the municipality offers an enabling environment for innovation,

b) municipal management provides leadership and support for innovation,

c) individual officials learn and expand their innovation capabilities, and

d) innovation is regarded as important for the municipality's activities and processes.

For the purposes of this paper, only two of the four constructs, i.e. organisational enablers of innovation and individual learning activities, are unpacked. Table 2 presents the overall maturity level descriptors which are adapted for each question (i.e. item) in the framework.

[Insert Table 2]

\subsection{Innovation Networks}

The observations regarding networking and collaboration are based on qualitative data. We interviewed four senior officials at the DST, three of the IPRDP programme managers, four senior municipal officials at four different municipalities and three representatives of three 
different government partners. With the exception of the municipal officials these actors were instrumental in identifying the 23 demonstration municipalities. In February 2016, the eight innovation demonstration teams presented their experiences at a workshop where the research team interrogated their experiences. This was followed up with email correspondence to clarify experiences. Further information on networking was obtained through research visits and discussions with officials from the district and local municipalities where the eight technologies were demonstrated.

\section{Findings}

\subsection{Community Participation in Public Sector Innovations}

Within a democratic landscape based on the principles of a human rights oriented developmental state and IID, PSI must foster inclusiveness beyond simply providing innovations in areas where they have limited collaboration and understanding of local needs and circumstances. The state and its agents should extend their innovation activities to ensure active participation by identified users in the innovation process. If local needs and conditions are poorly understood, then the outcome is to simply include settlements into plans without knowing what is best and appropriate for these settlements.

Table 3 highlights the limited engagement that municipalities and other IPRDP actors had with local residents in respect of demonstrating innovations. For example, we see that a small proportion of households $(28 \%)$ were aware of these technologies before they were demonstrated in their communities. These are households who reported being informed about the technological innovations planned to be rolled out, but no input was requested from them. Very few households (5\%) indicated that they were consulted (i.e. asked about their needs). Only $2 \%$ of the households were involved in choosing the innovation on offer, while only $1 \%$ reportedly provided inputs in the design of some of the technologies. 
[Insert Table 3]

Further qualitative observations highlight that, even for these households reportedly consulted, the process was ad hoc, left largely to community leaders and brokers with influence, who act as mediators between the community and the municipality. As a result, only the voices of the vocal and connected were heard. Interviews with local government officials reveal that sharing knowledge about the IPRDP innovations with the local population was not a priority. There is little evidence of broad-based, comprehensive community needs assessments done at sites to inform which technologies should be implemented in which areas. Our findings indicate that overall there has been limited consultation with community members about their immediate needs in relation to basic services, let alone participation in the design of the technologies, despite policy imperatives of IID and active citizen engagement in the development state. Von Hippel (2005), argues that participation in fact improves satisfaction because the participation of the users in the innovation process not only results in a product that meets their needs, but often inclusion in the innovation process itself can be a source of satisfaction.

\subsection{Municipal Innovation Capabilities for Enhancing Basic Services}

The overall mean for all response across the four MIMI constructs amounted to 2.6 when all responses are taken together from the two survey rounds. In round one the score across constructs was 2.4 and in round two it rose slightly to 2.7 , which points to an incremental increase in innovation capabilities or maturity between round one and two. It is postulated that learning in relation to innovation should contribute to enhanced innovation readiness and also maturity. However, the MIMI results show that learning by officials who have been involved in the IPRDP, and exposed to notions of innovation in relation to improving public services, have been minimal. Moreover, the organisational enablers scored lowest at 2.4 (Figure 2). When the median value is used organisational enablers scored 2.0 and the remaining three 
constructs scored 3.0. This points to officials at the municipalities surveyed considering their own maturity and that of their managers higher than the organisational maturity of the municipalities and environment in which they operate. This observation is consistent across round one and two of the survey, even when the results are considered separately, thereby strengthening our argument.

\section{[Insert Figure 2]}

For the purposes of this paper, constructs $\mathrm{A}$ and $\mathrm{C}$ are unpacked below. Figure 3 depicts the mean scores per item in relation to whether the organisation creates an enabling environment for innovation in relation to improving basic public service delivery. Physical resources for innovation and knowledge management in relation to innovation, external collaboration for innovation and overall organisational effectiveness in delivering services all received low scores. Whether innovation is linked to the overall organisational strategy and the allocation of human resources for innovation scored highest within this construct. In this regard, it should be reiterated that municipalities within the sample have been exposed to innovation for improved service delivery through the IPRDP. However, it appears that even though there is awareness around innovation it is not fully embedded within the organisational culture and operations.

\section{[Insert Figure 3]}

The individual learning construct considers the activities of individuals in relation to knowledge acquisition, learning and application. The item in relation to whether officials use new knowledge when implementing new approaches or solutions and external collaboration and partnerships scores lowest in the construct, while formal and informal networking behaviour scores slightly higher (Figure 4). However, the maturity levels in relation to collaboration and networking are quite low and the results indicate that these innovation principles are neither 
managed nor fully entrenched within municipalities. Municipalities report that they engage in networks, but it should be emphasised that these are a necessary element of the IPRDP (according to its design), as it is a networked partnership, but municipalities do not engage actively in networking activity on their own initiative per se.

[Insert Figure 4]

Qualitative observations regarding the capabilities, resources and innovation maturity of municipalities are illuminating. Access to adequate financial and skilled human resources are critical barriers in relation to basic service delivery in rural municipalities. This situation is confirmed in the MIMI data above. Often constituents cannot or will not pay for services (Seekings and Natrass, 2006). Lack of revenue hampers the activities of municipalities to provide basic services. In terms of human capabilities, national level IPRDP partners expressed scepticism about overall cooperation from the municipalities and particularly about the innovation capabilities of municipal actors involved in the IPRDP. At the local level, the capacity of bureaucrats to engage in and propel innovation are constrained not only by the lack of access to resources, including their own capability to democratise development and innovation, but also the nature of their employer institutions. This situation aligns with the innovation maturity data, which indicates that the ability of municipalities to provide an enabling environment to foster innovation are limited. High staff turnover in municipalities was cited as a general problem by many interviewees. It was said to also affect continuity of innovation demonstration planning and implementation. During interviews with national coordinators it was also pointed out that political tensions in certain areas and prolonged bureaucratic processes were key constraints to their effectiveness, as they relied on networks to see the process to completion. 


\subsection{Networking and Collaboration for Innovation on the Local Level}

Despite the developmental aims of the IPRDP, networking partnerships are generally observed to be fragmented and suffer from the lack of a local footprint. The IPRDP relies heavily on the NSI notion that emphases national STI partnerships and collaboration. However, most innovating agencies are based far from demonstration sites and are unfamiliar with the nuanced local social, economic, environmental and political circumstances. The result is a limited and mediated understanding by the DST and other national partners of the needs, challenges and opportunities encountered by municipal structures and particularly local residents. Mediation results in inappropriate technologies being demonstrated. For example, some pour flush toilets were demonstrated in areas that had water rather than those where water is scarce. Several challenges, including distance from the field sites, arose in the process that undermined the development of strong networks, trust and collaboration.

From interviews with scientists and municipal officials, misunderstandings between the different partners emerged about the purpose and role of the technology demonstrations. This situation is also partially due to the different needs and obligations of different partners. Municipal officials tend to prioritise the delivery of local Integrated Development Plan (IDP) commitments, while innovating agencies are inclined towards demonstrating the innovations, which in some instances differ from the priority needs and immediate concerns of the municipality and its constituents. Innovators are clear that demonstrations are only intended to illustrate that new technologies are feasible to improve existing systems, while officials are pressurised to reduce service delivery backlogs in the light of local community expectations. In some cases, municipal officials saw themselves and local residents as simply another phase in the research process. As many innovations had not yet been tested outside of research centres, demonstrations were seen as field research, "owned by" and the "responsibility of" the 
innovating agency rather than the municipality. In some cases, the innovating agency demonstrated with little local government participation, while in others firmer networks were established between local implementers and officials.

Many municipal officials were criticised by national STI partners for displaying limited interest in the demonstrations. At least two completely withdrew, while others partially withdrew in the sense that they decided to only engage in one activity. It should be noted that municipal officials have other commitments and devote most of their time and resources to those obligations, against which their performance is measured. The municipal innovation maturity findings confirm a lack of incentives for officials to engage with innovation. Given the 'demonstrative nature' of the innovations and their exclusion from prevailing IDPs, this situation meant officials had to do 'extra' work for which there was a real possibility of no recognition and queries about expenditure on unplanned activities. In other instances, the resources to introduce the demonstrations were not locally available, making them more expensive and costly to transport from the cities to selected outlying sites.

\section{Conclusions}

This research contributes to an emerging international literature on PSI and IID debates, in the context of developmental states, especially in the global South (see Habiyaremye et al., 2019; Hart et al., 2019; Heeks et al., 2014; Madumo, 2015; Petersen and Kruss, 2018; Phiri et al., 2018; Ramoroka et al., 2017; Rogerson, 2018; Schillo and Robinson, 2017; Sheikheldin and Devlin, 2018). Other countries with developmental ambitions when employing innovation can learn from the South African experience in demonstrating technological solutions to address service delivery in rural areas. Key learnings are outlined in the paragraphs below.

Our case analysis observes that the innovation focus of the IPRDP initiative can largely be understood as innovation 'pushed' into the targeted areas without taking appropriate stock of 
1) what exists locally i.e. considering how existing systems and technologies can be improved, or 2) considering particular local challenges or community needs. In other words, we see a clear pattern of top-down technology-push from urban STI actors accompanied by a dearth of rural bottom-up inclusion, let alone participation or the encouragement of this. This goes against the IID ideals of acknowledging and drawing in collaborators, such as users and co-innovators. Furthermore, participation, and collaboration among a group of stakeholders, aid technology localisation to ensure that technologies are locally functional and embedded for greater adoption on the local level (Sheikheldin and Devlin, 2018). Khambule (2018:97) emphasises the need of 'participatory approaches to development issues at the local level' which is lacking in the South African context. Our research shows that in the context of innovation for development, actors across the multiple hierarchies that comprise these 'networks' seldom interact or share knowledge. The implication is that needs of beneficiaries are often misunderstood, and innovative solutions struggle to achieve traction with local stakeholders to ensure wider roll-out and social benefit from PSI initiatives. In fact, their demonstrative nature means that local actors consider innovations to be experiments rather than solutions to their continued challenges. Moreover, Wild (2015) notes that post-pilot/-demonstration roll-out of service delivery interventions is not viable in South Africa because of the high costs involved, which is especially true for service delivery in rural areas.

The evidence presented here concerning a case of pro-poor PSI resonates with arguments made in respect to South Africa being a transfer welfare type of developmental state in which state organs and partners struggle to implement inclusive development and innovation in a democratic fashion that contributes to the delivery of meaningful basic services at local level. Key reasons are that actors and agencies generally do not possess the necessary features of strongly linked (networked), collaborative (inclusive and participatory) structures with sustainable resources - particularly funding and human capabilities. Rural South Africa 
provides a canvas for understanding the dynamics involved in introducing largely untried innovations in poorly understood localities. The intentions may be benign, and in line with a developmental state framework, but they are largely redistributive and top-down, meeting resistance in various ways from the local officials who are expected to operationalise these demonstrations.

District and local municipalities have a crucial mandate in extending the national development agenda of the South African state (NPC, 2012; RSA, 1998). This agenda includes the embodiment of 'the democratic culture within municipalities' (Madumo 2015: 154); a culture that should be extended to service delivery and innovation activities. Therefore, community participation is crucial in democratic development state and IID debates and should accordingly be prioritised by those tasked with PSI ensuring pro-poor benefits. The IPRDP process shows that innovating agencies at all levels, tasked with implementation, appear to have limited understanding of the theory and the practice required to introduce innovations that can drive improved basic services, inclusion and governance in these areas. Innovators simply demonstrate innovations that have seeming potential but without thorough awareness of local political, social, economic and geographical challenges (Hart et al., 2019). In fact, a first step might be to consider more socially-oriented innovations to address participation and communication obstacles before focusing on technical service solutions. By socially-oriented, we mean innovations that will lead to improved engagement with constituents and better interactions amongst national and local actors. Our findings further reveal that the constrained structure and functioning of STI networks, along with limited participation and inclusion of users, and the capacity of existing government institutions and officials are serious obstacles to the contribution of STI to developmental local government performance in South Africa.

The implications of our findings are that government and its STI partners need to revisit their processes and practices of IID, look at innovative ways to strengthen local institutional 
structures and the human capabilities of institutions and personnel to achieve IID. In this regard, we maintain that concerted collaborative efforts are needed by several national departments to ensure the embeddedness of a truly IID focus in the local government space to bring about development with pro-poor benefits if local government is to be developmental in its performance and outcomes. Greater emphasis must be placed on learning for PSI actors through knowledge networks within the sphere of local government, but which traverse the national and local levels (Booyens et al., 2018). Learning is of central importance for open, interactive or networked approaches to innovation (Klijn and Koppenjan, 2016; Lundberg and Hovik, 2014; Lundvall, 2009, von Hippel, 2005). It is argued that the role, structure and governance of the public sector, particularly local government, needs to be revisited in order to make provision for collaboration and networking in order to foster innovation for social development and economic growth (see Charles et al., 2017) as proposed in the NDP. Simply invoking the IID rhetoric is insufficient, as this paper illustrates. In order to enjoy a measure of success in terms of developmental states and IID, similar conditions are necessary: the encouragement and fostering of active participation by all stakeholders; sufficient financial resources and human capabilities at all levels; and strong collaborative and cohesive networks with similar purposes in mind. Once these form part of practice we are likely to see better implementation of IID.

\section{Acknowledgements}

We acknowledge the financial support of the Department of Science and Technology (DST) for our involvement in the Monitoring and Evaluation of the IPRDP from which we drew our analysis and argument. We also acknowledge the interaction of colleagues at the HSRC and fieldworkers who collaborated on the research. We thank Johann Booyens for assistance with the map. We thank the editor and the two anonymous peer reviewers for their insightful and relevant comments. This is our own original work and the views expressed do not reflect those 
of any other party. On behalf of all authors, the corresponding author states that there is no conflict of interest.

\section{References}

AG (Auditor General), 2019, Consolidated General Report on the Local Government Audit Outcomes, 2017 -18. Pretoria: Office of the Auditor General.

Albury, D., 2005, 'Fostering Innovation in Public Services', Public Money and Management, Vol. 25, No. 1, pp. 51-56.

Ansell, C. and J. Torfing, eds., 2014, Public Innovation through Collaboration and Design, Abingdon: Routledge.

AU (African Union), 2014, Science, Technology and Innovation Strategy for Africa 2024, Addis Ababa: African Union Commission.

Arnstein, S.R., 1969, 'A ladder of citizen participation', Journal of the American Institute of Planners, Vol. 35, No. 4, pp. 216-224.

Booyens, I. and T.G.B. Hart, 2019, Innovation in a changing South Africa: extant debates and critical reflections, in J. Knight and C.M. Rogerson, eds, Geography of South Africa Contemporary Changes and New Directions, Cham: Springer International, pp. 269-278.

Booyens, I., T.G.B. Hart and K.H. Ramoroka, 2018, 'Local innovation networking dynamics: evidence from South Africa', The European Journal of Development Research, Vol. 30, No. 4, pp. 749-767.

Behuria, P. and T. Goodfellow, 2018, 'Leapfrogging Manufacturing? Rwanda's Attempt to Build a Services-Led "Developmental State", The European Journal of Development Research, DOI: https://doi.org/10.1057/s41287-018-0169-9.

Bernard, P. and G. Boucher, 2007, 'Institutional competitiveness, social investment, and welfare regimes', Regulation \& Government Vol. 1, No. 3, pp. 213- 229. 
Bland, T., B. Bruk, D. Kim and K.T. Lee, 2010, 'Enhancing Public Sector Innovation: Examining the Network-Innovation Relationship', The Innovation Journal: the Public Sector Innovation Journal, Vol. 15, No. 3, pp. 1-17.

Bloch, C. and M.M. Bugge, 2013, 'Public sector innovation — From theory to measurement', Structural Change and Economic Dynamics Vol. 27, pp. 133-145.

Burger P., 2014, 'Facing the Conundrum: How Useful is the Developmental State Concept in South Africa', South African Journal of Economics, Vol. 82, No. 2, pp. 159-180.

Charles, G., S. Jeppesen, P. Kamau and P. Kragelund, 2017, 'Firm-level perspectives on statebusiness relations in Africa: the food-processing sector in Kenya, Tanzania and Zambia', Forum for Development Studies, Vol. 44, No. 1, pp. 109-131.

Chang, H- J., 2010, How to 'do' a developmental state: Political, organisational and human resource requirements for the developmental state, in O. Edigheji, ed., Constructing $a$ democratic developmental state in South Africa: Potentials and challenges, Cape Town: HSRC Press, pp. 82-96.

Cornwall, A., 2008, Unpacking 'Participation': Models, Meanings and Practices. Community Development Journal, Vol. 43, No. 3, pp. 269-283.

Cozzens, S and J, Sutz, 2014 Innovation in Informal Settings: Reflections and Proposals for a Research Agenda. Innovation and Development Vol 4, No. 1, pp. 5-31.

Djellal, F., F. Gallouj and I. Miles, 2013, 'Two decades of research on innovation in services: Which place for public services?', Structural Change and Economic Dynamics Vol. 27, pp. 98-117.

DST (Department of Science and Technology), 2013, Innovation Partnership for Rural Development Business Plan: Socioeconomic Partnerships, General Budget Support submitted to Department of National Treasury Republic of South Africa, Pretoria.

DST, 2015, Innovation for Local Economic Development: Strategy Document 2016-2020, Pretoria: DST.

DST, 2017, Draft White Paper on Science and Technology, Pretoria: DST. 
Evans, P., 2010, Constructing the 21st century developmental state: Potentialities and pitfalls, in O. Edigheji, ed., Constructing a democratic developmental state in South Africa: Potentials and challenges, Cape Town: HSRC Press, pp. 37-58.

Foster, C, and R, Heeks, R, 2013, Conceptualising Inclusive Innovation: Modifying Systems of Innovation Frameworks to Understand Diffusion of New Technology to Low Income Consumers, European Journal of Development Research, Vol. 25, No. 3, pp. 333-355.

Habiyaremye, A., G. Kruss and I. Booyens, 2019, Innovation for inclusive rural transformation: the role of the state, Innovation and Development, DOI: https://doi.org/10.1080/2157930X.2019.1596368

Hart, T. G., I. Booyens, B. Fakudze and S. Sinyolo, 2019, 'Reflections on demonstrating development-oriented innovations in South Africa', South African Journal of Science, Vol. 115, No. 1-2, pp. 5-8.

Hart, T., P. Jacobs, B. Letty, K.H. Ramoroka, J. Mangqalaza, A. Mhula and M. Ngwena, 2014, Promoting innovation for inclusive rural transformation in South Africa, Cape Town: HSRC.

Hart, T., K.H. Ramoroka, P.T. Jacobs and B. Letty, 2015, Revealing the social face of innovation, South African Journal of Science, Vol. 111, No. 9/10, pp. 109-114.

Heeks R., M. Amalia, R. Kintu and N. Shah, 2013, Inclusive innovation: Definition, conceptualisation and future research priorities, IDPM Development Informatics Working Paper no.53. Manchester, UK: University of Manchester.

Heeks R., C. Foster and Y. Nugroho, 2014, New models of inclusive innovation for development. Innovation and Development Vol. 4, No. 2, pp. 175-185.

HSRC (Human Sciences Research Council), 2016, Innovations Dynamic Report 1: Implementation Process of Service Delivery Technologies in Priority Municipalities, Pretoria: HSRC

Johnson, C., 1982, MITI and the Japanese miracle: The growth of industrial policy, 1925 1975, Redwood City: Stanford University Press. 
Johnson, C., 1999, The developmental state: Odyssey of a concept, in M. Woo-Cumings, ed., The_developmental state, New York: Cornell University Press, pp. 32-60.

Khambule, I., 2018, 'Imagining an institutionalised social dialogue in the South African local government-led development landscape', Forum for Development Studies, Vol. 45, No. 1, pp. 97-117.

Klijn, E.H. and J. Koppenjan, 2016, Governance Networks in the Public Sector, Abingdon: Routledge.

Kruss, G. and J. Lorentzen, 2011, The South African Innovation policies: potential and constraint, in E. Cassiolato and V. Vitorino, Eds., BRICS and Development Alternatives: Innovation Systems and Policies, London: Anthem Press, pp. 163-190

Lewis, M.J. and L.M. Ricard, 2014, Innovation capacity in the public sector: structures, networks and leadership. Learning from Innovation in Public Sector Environments (LIPSE) Project Working Paper No 3. Rotterdam: Erasmus University Rotterdam.

Lundberg, A.K.A. and S. Hovik, 2014, Inclusive and broad mobilization in collaborative rural governance? The case of Natural Park Management Boards in Norway, Paper presented at the European Consortium for Political Research (ECPR) Joint Session of Workshops, Salamanca. 10-14 April 2014.

Lundvall, B-A., 2009, 'Innovation as an interactive process: user-producer interaction to the National System of Innovation', African Journal of Science, Technology, Innovation and Development, Vol. 1, Nos, 2\&3, pp. 10-34.

Madumo, O.S., 2015, 'Developmental Local Governmental Challenges and Progress in South Africa', Administratio Publica, Vol. 33, No. 2, pp. 153-166.

Meinott, M and G, Masterson, 2018, State Capture in Africa: Old Threats, New Packaging. Johannesburg: EISA (Electoral Institute for Sustainable Democracy in Africa).

Mulgan, G. and D. Albury, 2003, 'Innovation in the public sector', http://www.sba.oakland.edu/faculty/mathieson/mis524/resources/readings/innovation/in novation_in_the_public_sector.pdf. 
Ndabeni, L., C.M. Rogerson and I. Booyens, 2016, 'Innovation and local economic development policy in the global South: new South Africa perspectives', Local Economy Vol. 31,Nos. 1\&2, pp. 299-311.

Nel, E., T. Binns and D. Bek, 2009. 'Misplaced expectations? The experience of applied local economic development in post-apartheid South Africa', Local Economy, Vol. 24, No. 3, pp. 224-237.

Nordhaug, K., 2012, 'China's Decentralized and Inegalitarian Developmental State', Forum for Development Studies, Vol. 39, No. 3, pp. 407-433.

NPC (National Planning Commission), 2012, Our future-make it work: National Development Plan 2030, Pretoria: NPC, The Presidency, Republic of South Africa.

OECD (Organisation for Economic Cooperation and Development), 2012, Innovation for development: a discussion of the issues and an overview of work of the OECD directorate for Science, Technology and Innovation, Paris: OECD.

OECD,2015, Innovation Policies for Inclusive Development: Scaling Up Inclusive Innovations. Paris: OECD.

Petersen, I. H., G. Kruss, J.A. Rust and A. Tele, 2016, 'Is South Africa ready for "Innovation for Inclusive Development"? A systematic review across national policy', Cape Town: HSRC.

Petersen, I. H. and G. Kruss, 2018, 'Promoting alignment between innovation policy and inclusive development in South Africa', Development Southern Africa, DOI: https://doi.org/10.1080/0376835X.2018.1490175

Phiri, M.Z., N. Molotja, H. Makelane, T. Kupamupindi and C. Ndinda, 2016, 'Inclusive innovation and inequality in South Africa: a case for transformative social policy', Innovation and Development, Vol. 6, No. 1, pp. 123-139.

Ramoroka, K.H., I. Booyens and P.T. Jacobs, 2017, Innovation by local government for improved basic service delivery in South Africa, IPRDP Concept Paper \#1, Cape Town: HSRC. 
Rodríguez-Pose, A. and M. Di Cataldo, 2015, 'Quality of government and innovative performance in the regions of Europe', Journal of Economic Geography, Vol. 15, No. 4, pp. 673-706.

Rogerson, C.M., 2014, 'Reframing place-based economic development in South Africa: The example of local economic development', Bulletin of Geography: Socio-Economic Series, Vol. 24, No. 24, pp. 203-218.

Rogerson, C.M.,2018, 'Innovation-driven local economic development: in search of best practice implementation for South Africa', EuroEconomica, Vol. 37, No. 2,pp. 21-34

RSA (Republic of South Africa), 1996a, White Paper on Science and Technology, Pretoria: Government Printer.

RSA, 1996b, Constitution of the Republic of South Africa, Act 108 of 1996, Pretoria: Government Gazette.

RSA, 1998, White Paper on Local Government, Pretoria: Government Printer.

Schillo, R.S. and R.M. Robinson, 2017, 'Inclusive Innovation in Developed Countries: The Who, What, Why and How', Technology Innovation Management Review, Vol. 7, No. 7, pp. 34-46.

Seekings, J. and N. Nattrass, 2006, Class, Race and Inequality in South Africa, Scottsville: University of KwaZulu-Natal Press.

Sheikheldin, G.H. and J.F. Devlin, 2018, 'Agents of Technology Localization in East Africa: Case Studies of Social Enterprises in Tanzania', Forum for Development Studies, DOI: https://doi.org/10.1080/08039410.2018.1534751.

Stats SA (Statistics South Africa), 2017, Poverty trends in South Africa: An examination of absolute poverty between 2006 and 2015, Pretoria: Statistics South Africa.

Tria Kerkvliet, B.J., 2010, 'Governance, Development, and the Responsive-Repressive State in Vietnam', Forum for Development Studies, Vol. 37, No. 1, pp. 33-59.

Van der Berg, S., K. Siebrits and B. Lekezwa, 2010, Efficiency and equity effects of social grants in South Africa, Stellenbosch Economic Working Papers 15/10, Stellenbosch: 
Department of Economics and Bureau for Economic Research, University of Stellenbosch.

Van der Waldt, G., 2015, Local Governance: Leading Sustainable Communities, Johannesburg: University of Johannesburg.

Von Hippel, E., 2005, Democratising Innovation, Cambridge, Massachusetts: MIT Press.

Walwyn, D. and L. Cloete, 2018, 'Draft White Paper on Science, Technology and Innovation neglects to prioritise issues of performance and human capability', South African Journal of Science, Vol. 114, No. 11/12, pp. 1-6.

Wild, S., 2015, Innovation: Shaping South Africa through science, Johannesburg: Macmillan.

World Bank, 2018, Overcoming poverty and inequality in South Africa: an Assessment of Drivers, Constraints and Opportunities, Washington, DC: The World Bank 